OPEN ACCESS

Edited by:

Mark A. Elliott,

National University of Ireland

Galway, Ireland

Reviewed by:

Joshua T. Kantrowitz,

Columbia University, United States

Joanne P. M. Kenney,

Royal College of Surgeons

in Ireland, Ireland

*Correspondence:

Masayoshi Kurachi

kurachi.masa@outlook.jp

Specialty section:

This article was submitted to

Psychopathology,

a section of the journal

Frontiers in Psychiatry

Received: 20 November 2017

Accepted: 30 January 2018

Published: 19 February 2018

Citation:

Kurachi M, Takahashi T, Sumiyoshi T, Uehara T and Suzuki M (2018) Early Intervention and a Direction of Novel

Therapeutics for the Improvement of

Functional Outcomes in Schizophrenia: A Selective Review.

Front. Psychiatry 9:39.

doi: 10.3389/fpsyt.2018.00039

\section{Early Intervention and a Direction of Novel Therapeutics for the Improvement of Functional Outcomes in Schizophrenia: A Selective Review}

\author{
Masayoshi Kurachi ${ }^{1 *}$, Tsutomu Takahashi ${ }^{2}$, Tomiki Sumiyoshi ${ }^{3}$, Takashi Uehara ${ }^{4}$ \\ and Michio Suzuki²

\begin{abstract}
'Arisawabashi Hospital, Toyama, Japan, ${ }^{2}$ Department of Neuropsychiatry, Graduate School of Medicine, University of Toyama, Toyama, Japan, ${ }^{3}$ Department of Clinical Epidemiology, Translational Medical Center, National Center of Neurology and Psychiatry, Tokyo, Japan, ${ }^{4}$ Department of Neuropsychiatry, Kanazawa Medical University, Kanazawa, Japan
\end{abstract}

Background: A recent review reported that the median proportion of patients recovering from schizophrenia was $13.5 \%$ and that this did not change over time. Various factors including the duration of untreated psychosis, cognitive impairment, negative symptoms, and morphological changes in the brain influence the functional outcome of schizophrenia. The authors herein reviewed morphological changes in the brain of schizophrenia patients, effects of early intervention, and a direction of developing novel therapeutics to achieve significant improvement of the functional outcome.

Methods: A selective review of the literature including studies from our department was performed.

Results: Longitudinal structural neuroimaging studies on schizophrenia revealed that volume reductions in the peri-Sylvian regions (e.g., superior temporal gyrus and insula), which are related to positive psychotic symptoms, progress around the onset (critical stage) of schizophrenia, but become stable in the chronic stage. On the other hand, morphological changes in the fronto-thalamic regions and lateral ventricle, which are related to negative symptoms, neurocognitive dysfunction, and the functional outcome, progress during both the critical and chronic stages. These changes in the peri-Sylvian and fronto-thalamic regions may provide a pathophysiological basis for Crow's twosyndrome classification. Accumulated evidence from early intervention trials suggests that the transition risk from an at-risk mental state (ARMS) to psychosis is approximately 30\%. Differences in the cognitive performance, event-related potentials (e.g., mismatch negativity), and brain morphology have been reported between ARMS subjects who later developed psychosis and those who did not. Whether early intervention for ARMS significantly improves the long-term recovery rate of schizophrenia patients remains unknown. With respect to the development of novel therapeutics, animal models of schizophrenia based on the $N$-methyl-D-aspartate receptor hypofunction hypothesis successfully mimicked behavioral changes associated with cognitive impairments 
characteristic of the disease. Furthermore, these animal models elicited histological changes in the brain similar to those observed in schizophrenia patients, i.e., decreased numbers of parvalbumin-positive interneurons and dendritic spines of pyramidal neurons in the frontal cortex. Some antioxidant compounds were found to ameliorate these behavioral and histological abnormalities.

Conclusion: Early intervention coupled with novel therapeutics may offer a promising approach for substantial improvement of the functional outcome of schizophrenia patients.

Keywords: schizophrenia, functional outcome, early intervention, $\mathbf{N}$-methyl-D-aspartate receptor, structural MRI

\section{INTRODUCTION}

The functional outcome of schizophrenia patients has been a major concern in psychiatry. A systematic review of 50 studies from 1921 to 2011 (1) demonstrated that the median proportion of patients recovering from schizophrenia was $13.5 \%$ and that this did not change over time despite the progress in treatment in recent decades.

Various factors have been reported to influence the course and outcome of schizophrenia patients. The predictors of the 2-year outcome in the WHO 10-country study (2) were the age, sex, marital status, mode of onset (acute or insidious), duration of untreated psychosis (DUP), premorbid psychosocial functioning, close friends, drug abuse, and sociocultural setting, i.e., a developing versus a developed country. However, most of these factors except DUP and drug abuse are beyond clinical control.

Other important factors include neurocognitive dysfunctions (3-6), negative symptoms $(7,8)$, and alterations in brain morphology (9-11). Although antipsychotic medications are effective for reducing positive psychotic symptoms, these symptoms including first-rank symptoms showed no significant correlation with the outcome of schizophrenia patients $(2,3)$. The improvements of cognitive impairment and negative symptoms are not satisfactory with the current treatment, and they may have pathophysiologies that differ from those of positive symptoms. It should be noted that there is compelling evidence that the progressive enlargement of the lateral ventricles is closely related to the outcome of schizophrenia patients (9-11). These morphological brain changes should be the target of novel therapeutics.

Duration of untreated psychosis, neurocognitive dysfunctions, negative symptoms, and brain morphology are potentially controllable by medicine. An effective method to substantially improve the functional outcome would be to develop a therapeutic strategy to control these factors. Therefore, the authors reviewed studies on morphological changes in the brain of schizophrenia patients, early intervention, and a direction of developing novel therapeutics.

\section{METHODS}

The method was a selective review of the literature including studies from the authors' department. Concerning studies on morphological brain changes associated with functional outcome in schizophrenia patients, the authors searched PubMed using the keywords: "MRI," "functional outcome," and "schizophrenia." Combination with the author's previous manual list resulted in 15 publications relevant to the present theme as shown in Table 1. Some of these studies were the starting point of this review. In the section of novel therapeutics, potential candidate compounds are described, capable of ameliorating the histological brain changes in schizophrenia patients.

\section{STRUCTURAL MAGNETIC RESONANCE IMAGING STUDIES ON SCHIZOPHRENIA}

\section{Region of Interest Method}

Structural magnetic resonance imaging (sMRI) studies using the region of interest method have demonstrated significant volume reductions in schizophrenia patients mainly in three brain regions: the medial temporal lobe structures (hippocampus and amygdala), peri-Sylvian regions (superior temporal gyrus and insula), and prefrontal areas including fronto-thalamic connections, compared with healthy control subjects. We noted the difference in brain morphology between patients with schizophrenia and subjects with schizotypal (personality) disorder or first-degree relatives of the patients to differentiate the disease process from risk- or vulnerability-associated changes.

Among the three regions, volume reductions in the medial temporal lobe structures have been confirmed in schizophrenia patients (24). However, these changes may represent a risk of or vulnerability to the disease, as pointed out by Seidman et al. (25), since these changes were also seen to the same extent in schizotypal (personality) disorder and first-degree relatives of patients with schizophrenia (25-27). A meta-analysis of longitudinal sMRI studies on schizophrenia (28) showed no evidence to suggest progressive medial temporal lobe involvement.

Volume reductions in the superior temporal gyrus were seen in both schizophrenia and schizotypal disorder patients $(29,30)$. However, the changes in schizophrenia patients were more widespread than in schizotypal disorder patients: the changes extended to Heshcl's gyrus and the planum polare in schizophrenia, but not in schizotypal disorder (30). In longitudinal studies, progressive decreases in the gray matter volume in the left superior temporal gyrus were noted in first-episode schizophrenia patients $(31,32)$. During the chronic stage, however, no significant progressive changes of the superior temporal gyrus were seen in schizophrenia patients using the region of interest method $(33,34)$. 
TABLE 1 | Morphological changes in the brain related to the functional outcome in schizophrenia patients.

\begin{tabular}{|c|c|c|c|c|}
\hline Study & Year & Subjects & $\begin{array}{l}\text { Methods (intervals } \\
\text { between scans) }\end{array}$ & Findings \\
\hline Davis et al. (9) & 1998 & $\begin{array}{l}53 \text { chronic patients } \\
\text { (22 Kraepelinian and } 31 \text { non-Kraepelinian) }\end{array}$ & $\begin{array}{l}\text { Longitudinal CT (mean } \\
\text { intervals of } 5 \text { years) }\end{array}$ & $\begin{array}{l}\text { The ventricles showed a bilateral increase in size over 4-year } \\
\text { interval in the Kraepelinian subgroup, more marked in the left } \\
\text { hemisphere than the right }\end{array}$ \\
\hline Lieberman et al. (10) & 2001 & 51 first-episode patients and 13 controls & $\begin{array}{l}\text { Longitudinal MRI (at least } \\
12 \text { months) }\end{array}$ & $\begin{array}{l}\text { Progressive ventricular enlargement in patients with poor } \\
\text { outcome schizophrenia }\end{array}$ \\
\hline Ho et al. (12) & 2003 & 73 recent-onset patients and 23 controls & $\begin{array}{l}\text { Longitudinal MRI (mean } \\
\text { intervals of } 3 \text { years) }\end{array}$ & $\begin{array}{l}\text { Patients with poor outcome had a greater lateral ventricular } \\
\text { enlargement over time than patients with good outcome }\end{array}$ \\
\hline Brickman et al. (13) & 2004 & 106 chronic patients and 42 controls & MRI & $\begin{array}{l}\text { Patients showed significantly smaller thalamic areas, and the } \\
\text { effects were most marked in the patients with poor outcome }\end{array}$ \\
\hline Mitelman et al. (14) & 2005 & 37 chronic patients and 37 controls & $\mathrm{MRI}$ & $\begin{array}{l}\text { Poor outcome subgroup exhibited significant bilateral gray } \\
\text { matter deficits in posterior cingulate and retrosplenial cortices } \\
\text { compared to good outcome patients }\end{array}$ \\
\hline Cahn et al. (15) & 2006 & 31 first-episode patients & $\begin{array}{l}\text { Longitudinal MRI (1 year) } \\
\text { and 5-year outcome }\end{array}$ & $\begin{array}{l}\text { Progressive brain volume changes of gray matter during the } \\
\text { first year of illness were significantly associated with clinical and } \\
\text { functional outcome } 5 \text { years after the first episode }\end{array}$ \\
\hline Mitelman et al. (16) & 2006 & $\begin{array}{l}104 \text { chronic patients ( } 51 \text { good outcome } \\
\text { and } 53 \text { poor outcome) and } 41 \text { controls }\end{array}$ & Diffusion tensor imaging & $\begin{array}{l}\text { Overall white matter fractional anisotropy was reduced in } \\
\text { patients with poor outcomes in both hemispheres }\end{array}$ \\
\hline Wood et al. (17) & 2006 & 46 patients with first-episode psychosis & Proton MRS & $\begin{array}{l}\text { Low scores on the NAA/Cr ratio in the prefrontal cortex were } \\
\text { related to poorer outcome }\end{array}$ \\
\hline van Haren et al. (11) & 2008 & 96 patients and 113 controls & $\begin{array}{l}\text { Longitudinal MRI (over } \\
5 \text { years) }\end{array}$ & $\begin{array}{l}\text { Poor outcome patients showed more brain tissue loss during the } \\
\text { follow-up interval than good outcome patients }\end{array}$ \\
\hline Wobrock et al. (18) & 2009 & 45 first-episode patients & MRI, follow-up to 1 year & $\begin{array}{l}\text { A significant reduced area of the left anterior limb of the internal } \\
\text { capsule in patients with clinically relevant deterioration } \\
\text { compared to those with stable psychopathology }\end{array}$ \\
\hline Mitelman et al. (19) & 2009 & $\begin{array}{l}\text { Chronic schizophrenia ( } 26 \text { poor outcome } \\
\text { and } 23 \text { good outcome patients) and } 16 \\
\text { controls }\end{array}$ & $\begin{array}{l}\text { Longitudinal MRI } \\
\text { (4 years) }\end{array}$ & $\begin{array}{l}\text { The rate of decline in volumes of the putamen was greater in } \\
\text { patients with poor outcome than in the good outcome group }\end{array}$ \\
\hline Mitelman et al. (20) & 2010 & 49 chronic patients and 16 controls & $\begin{array}{l}\text { Longitudinal MRI } \\
\text { (4 years) }\end{array}$ & $\begin{array}{l}\text { Progressive enlargement of the posterior horn in the poor } \\
\text { outcome (Kraepelinian) group }\end{array}$ \\
\hline van Haren et al. (21) & 2011 & 96 patients and 113 controls & $\begin{array}{l}\text { Longitudinal MRI, vertex- } \\
\text { by-vertex basis ( } 5 \text { years) }\end{array}$ & $\begin{array}{l}\text { Frontal and temporal cortices showed excessive thinning over } \\
\text { time, possibly related to outcome and medication intake }\end{array}$ \\
\hline Tully et al. (22) & 2014 & 26 patients and 29 controls & $\begin{array}{l}\text { MRI, surface-based } \\
\text { morphometry }\end{array}$ & $\begin{array}{l}\text { Cognitive control fully mediated the relationship between cortical } \\
\text { thickness in the superior frontal gyrus and role functioning }\end{array}$ \\
\hline Dusi et al. (23) & 2017 & $\begin{array}{l}\text { Chronic schizophrenia ( } 35 \text { poor outcome, } \\
35 \text { good outcome patients, and } 76 \\
\text { controls) }\end{array}$ & $\begin{array}{l}\text { Longitudinal MRI } \\
\text { (3 years) }\end{array}$ & $\begin{array}{l}\text { At baseline, poor outcome patients showed significantly } \\
\text { decreased right dorsolateral prefrontal cortex (DLPFC) white } \\
\text { matter volumes compared to controls, with shrinkage of left } \\
\text { DLPFC white matter volumes at follow-up }\end{array}$ \\
\hline
\end{tabular}

Volume reduction in the insular cortex was noted in schizophrenia patients but not in schizotypal patients compared with healthy control subjects $(35,36)$. On longitudinal comparison, first-episode patients showed a significant gray matter reduction of the insular cortex over time compared with controls $(37,38)$. In chronic schizophrenia patients, however, no significant changes were found (38).

Thus, volume reductions in the superior temporal gyrus and insular cortex have been shown to progress during the first episode, but they may become stable in the chronic stage.

With regard to the prefrontal areas, schizophrenia patients showed reductions in the volume of the anterior cingulate gyrus, dorsolateral prefrontal areas (superior, middle, and inferior frontal gyri), and straight gyrus, while schizotypal patients had larger volumes of the bilateral middle frontal gyrus (26) or Brodmann area
10 (39) compared with healthy controls. Yamasue et al. (40) demonstrated that the effect size of volume reductions in schizophrenia patients was largest in the anterior cingulate gyrus among prefrontal and temporolimbic regions (superior temporal gyrus, amygdalehippocampus complex, insula, and anterior cingulate gyrus).

In longitudinal studies, early schizophrenia patients showed a progressive reduction in the frontal lobe white matter volume, which was associated with more negative symptoms (12). A meta-analysis of 27 longitudinal volumetric studies (28) revealed that patients with schizophrenia showed significantly greater decreases over time in the frontal gray and white matter, parietal white matter, and temporal white matter volumes than healthy controls. Thus, frontal lobe alterations in schizophrenia may progress in patients, at least in part, through the first episode and chronic stage. 
Slight but significant enlargement of the lateral ventricle, especially in the left hemisphere, is one of the most consistent morphological brain changes in schizophrenia patients $(41,42)$. This enlargement is most likely due to the volume reductions of the adjacent white matter of the brain. With regard to this, Suzuki et al. (43) and Zhou et al. (44) reported white matter reductions in the anterior limb of the internal capsule in schizophrenia patients. It is interesting to note that bidirectional glutamatergic frontothalamic fibers pass through the anterior limb of the internal capsule. In longitudinal studies on first-episode schizophrenia, it was found that poor outcome patients showed an increase in the ventricle volume over time, whereas the ventricle volume of good outcome patients and controls did not change (10). In chronic schizophrenia, progressive ventricle enlargement has also been reported in poor outcome patients $(9,11)$.

\section{Voxel-Based Morphometry (VBM)}

The VBM method has the advantage of being able to explore local morphological changes in the whole brain. Suzuki et al. (43) using voxel-based analysis, reported that the gray matter in schizophrenia patients was significantly reduced in the medial temporal, left superior temporal, left middle and inferior frontal, right inferior frontal, and bilateral anterior cingulate areas compared with healthy controls.

Kawasaki et al. (45) studied gray matter changes in schizophrenia and schizotypal disorder patients compared with healthy controls by VBM of three-dimensional MRI. They found that the volume of the medial temporal lobe structure and superior temporal gyrus was reduced in both schizophrenia and schizotypal disorder patients compared with healthy controls, whereas volume reductions in the frontal gyri were prominent only in schizophrenia patients.

Subsequent meta-analyses of VBM studies $(46,47)$ revealed gray matter reduction in a network of frontal, temporal, thalamic, and striatal regions in schizophrenia patients relative to healthy comparison subjects. Despite some discrepancies (48), these results are consistent with those using the region of interest method and support the view of Siever and Davis (49) and Kurachi (50) that frontal lobe alterations play a crucial role in the development of schizophrenia.

Honea et al. (51), using the VBM method, demonstrated that schizophrenia patients showed volume reductions in the bilateral superior and middle frontal gyri, left inferior frontal gyrus, and right thalamus compared with their unaffected siblings with no history. Furthermore, Hao et al. (52), using voxel-based analysis of diffusion tensor imaging, demonstrated that both schizophrenia patients and their healthy siblings showed reduced white matter fractional anisotropy in the left prefrontal cortex and hippocampus in comparison with healthy controls, while only schizophrenia patients exhibited reduced white matter fractional anisotropy in the left anterior cingulate cortex in comparison with both siblings and controls.

Thus, cross-sectional region of interest as well as VBM sMRI studies showed volume reductions in medial temporal lobe structures, peri-Sylvian regions, and prefrontal areas including fronto-thalamic connections in schizophrenia patients compared with healthy controls. Longitudinally, volume reduction in the peri-Sylvian regions (e.g., superior temporal gyrus and insula) progressed during the first episode, but became stable in the chronic stage. On the other hand, morphological changes in the frontal lobe and lateral ventricle progressed through the first episode and chronic stage.

\section{CLINICAL CORRELATES OF MORPHOLOGICAL CHANGES IN SCHIZOPHRENIA AND A PATHOPHYSIOLOGICAL MODEL}

Several studies have reported clinical correlates of morphological changes in schizophrenia patients. Auditory hallucinations have been reported to be associated with gray matter volume reductions in the left (anterior) superior temporal gyrus and Heschl's gyri by the region of interest method $(30,53)$ and a subsequent VBM study (54).

Shenton et al. (55) reported that the severity of formal thought disorder was negatively correlated with the volume of the left posterior superior temporal gyrus, and a VBM study (56) also showed the correlation with the gray matter volume reduction within the left temporal lobe in addition to the right middle orbital and cuneus/lingual gyri.

According to the study by Takahashi et al. (38), the gray matter loss of the left insular cortex over time in first-episode patients was correlated with the severity of positive and negative symptoms on follow-up.

Thus, the structural alterations in the peri-Sylvian regions (e.g., superior temporal gyrus and insula) were related to positive psychotic symptoms such as auditory hallucinations, thought disorder, and possibly delusions.

With regard to negative symptoms, a correlation with functional and structural alterations in prefrontal areas and the medial thalamus has been reported $(12,57)$. This correlation was clearly evidenced by a VBM study (58) although insular gray matter volume may also be involved in negative symptoms (59).

In addition to positive and negative symptoms, neurocognitive dysfunctions, especially executive dysfunctions, are an important aspect of schizophrenia, since they are related to the functional outcome (3). A meta-analysis of 41 functional neuroimaging studies of the executive function in schizophrenia patients (60) revealed that patients with schizophrenia showed reduced activity in the dorsolateral prefrontal cortex, anterior cingulate cortex, and mediodorsal nucleus of the thalamus. Consistent with this, a sMRI study showed that the executive dysfunctions were correlated with volume reduction in the bilateral dorsolateral prefrontal cortex in schizophrenia patients (61). Regarding memory impairment, deficits in memory organization have been shown to be a characteristic feature in schizophrenia patients (62). Memory organization deficits were related to volume reduction in the prefrontal cortex (63).

Studies on the morphological brain changes related to the functional outcome in schizophrenia patients are summarized in Table 1. First, in accordance with the report by Keefe et al. (64), which suggested morphological brain changes, e.g., ventricle enlargement, in the Kraepelinian (most severely deteriorated) chronic schizophrenic patients, progressive enlargement of the 
lateral ventricle has been one of the most consistent findings in poor outcome patients (9-12). This enlargement is at least in part derived from the volume reduction of the anterior limb of the internal capsule, through which the bidirectional fronto-thalamic fibers pass. Volume reductions in the anterior limb of the internal capsule in schizophrenia patients were related to verbal and spatial memory (65) and the social outcome (18). Furthermore, a marked reduction in sleep spindles in schizophrenia patients also suggests impairment of the thalamo-frontal circuitry in this disease (66-68).

Second, prefrontal alterations were reported to be related to a poor outcome in schizophrenia patients $(17,22,23)$. Notably, Tully et al. (22) reported that the relationship between the prefrontal alterations and poor outcome were mediated by impaired cognitive control (category fluency).

Third, other brain areas were also mentioned $(11,16,21)$. van Haren et al. (21) reported progressive decreases in the cortical thickness in the superior temporal cortex as well as anterior cingulate cortex in patients with poor outcomes based on the vertex-by-vertex method. These findings appear to disagree with the results using the region of interest method $(33,34)$. In addition, the study by van Haren et al. is characterized by a large sample with a wide ranging duration of illness.

With regard to outcome measures, clinical criteria by Keefe et al. (64) have been frequently used as well as the Global Assessment of Functioning (GAF) score. In 2013, the American Psychiatric Association (69), instead of the GAF, adopted the WHO Disability Assessment Schedule (WHODAS 2.0) in Diagnostic and Statistical Manual of Mental Disorders-5.

To briefly summarize, volume reductions in the peri-Sylvian regions are mainly related to positive symptoms, whereas alterations in the regions composing the fronto-thalamic circuitry are mainly related to negative symptoms, executive functions, and the functional outcome. These two types may be called the periSylvian type and fronto-thalamic type, respectively, and this model may provide a pathophysiological basis for Crow's (70) positive and negative syndrome classification (Table 2). Traditional simple

TABLE 2 | Pathophysiological modeling of schizophrenia.

\begin{tabular}{lll}
\hline Type & Peri-Sylvian type & Fronto-thalamic type \\
\hline $\begin{array}{l}\text { Brain regions } \\
\text { involved }\end{array}$ & $\begin{array}{l}\text { Superior temporal gyrus, } \\
\text { insula }\end{array}$ & $\begin{array}{l}\text { Anterior cingulate gyrus } \\
\text { Dorsolateral prefrontal gyrus } \\
\text { Dorsomedial thalamus }\end{array}$ \\
\hline $\begin{array}{l}\text { Chemical } \\
\text { pathology }\end{array}$ & $\begin{array}{l}\text { Excessive DA } \\
\text { neurotransmission }\end{array}$ & $\begin{array}{l}\text { Imbalance in glutamate-GABA } \\
\text { system }\end{array}$ \\
\hline $\begin{array}{l}\text { Clinical } \\
\text { manifestations }\end{array}$ & $\begin{array}{l}\text { Positive symptoms } \\
\text { (delusions, hallucinations, } \\
\text { disorganized speech) }\end{array}$ & $\begin{array}{l}\text { Negative symptoms (diminished } \\
\text { emotional expression, avolition) } \\
\text { Executive dysfunctions } \\
\text { Disability in social functioning }\end{array}$ \\
\hline Clinical course & $\begin{array}{l}\text { Progressive during the } \\
\text { prodromal and first-episode } \\
\text { stages, but stable in the } \\
\text { chronic stage }\end{array}$ & $\begin{array}{l}\text { Progressive both in the first } \\
\text { episode and chronic stages }\end{array}$ \\
\hline Responsiveness & $\begin{array}{l}\text { Responsive } \\
\text { to treatment }\end{array}$ & \\
\hline
\end{tabular}

$D A$, dopamine; GABA, gamma-aminobutyric acid. type schizophrenia is a good example of the fronto-thalamic type, as evidenced by Suzuki et al. (71). This model could explain why positive psychotic symptoms are not significantly correlated with the functional outcome, since it proposes that positive psychotic symptoms and the functional outcome have distinct underlying pathophysiologies.

From the viewpoint of this pathophysiological model, it is noteworthy that the morphological brain changes in schizophrenia patients of discordant and concordant twins are not identical. According to a VBM study (72), patients with schizophrenia of discordant twins showed volume reductions in peri-Sylvian regions as well as the fronto-thalamic circuitry, whereas patients with schizophrenia of concordant twins showed volume reductions in the fronto-thalamic circuitry, but not in the peri-Sylvian regions.

\section{EARLY INTERVENTION}

Early intervention consists of two parts: one is early intervention in first-episode psychosis, and the other is that toward the prodromal phase. The main aim of early intervention in firstepisode psychosis is to reduce the DUP. Hegelstad et al. (73) studied the effect of this reduction on the 10-year outcome. As a result, $30.7 \%$ of the patients from the early-detection area (a median DUP of 5 weeks) fulfilled recovery criteria, while only $15.1 \%$ of the patients from the usual-detection area (a median DUP of 16 weeks) did so. For the further improvement of the recovery rate, early intervention toward the prodromal phase would be required.

Since a prodrome is a retrospective concept, the term of "at-risk mental state (ARMS)" has been used in prospective trials (74). Early intervention for help-seeking individuals with ARMS will be necessary, since such subjects suffer the distress of symptoms and are liable to develop disability in functioning.

Importantly, in longitudinal studies, volume reductions in the planum temporale, caudal superior temporal gyrus, and insular cortex progressed in ultra-high-risk (UHR) subjects who later developed psychosis compared with controls or UHR subjects who did not develop it $(32,75)$. Hence, volume reductions in the peri-Sylvian regions (e.g., superior temporal gyrus and insula) have been shown to progress during the prodromal phase.

The transition risk from ARMS to psychosis was $29-36 \%$ over a 2- to 3-year follow-up (76). This figure is markedly higher than the incidence rate of psychosis in the general population, but it should be noted that two-thirds of subjects were false positive using these ARMS criteria.

Thus, for an indicated early intervention, it is necessary to diagnose those who are truly in the prodromal phase among ARMS patients. Effective examination would detect the subclinical pathophysiological process. In accordance with this, several candidate biomarkers have been reported, such as the neurocognitive function, event-related potential, and sMRI. In addition, the Minnesota Multiphasic Personality Inventory may be a useful tool to assess the risk of transition to psychosis.

The cognitive function is impaired in ARMS patients as well as in first-episode and chronic schizophrenia patients (6). In particular, the verbal memory and executive functions of ARMS 
subjects who later developed psychosis were reported to be lower than in those who did not develop psychosis (77-79). Notably, ARMS patients who developed psychosis or did not show remission during the 2-year follow-up showed a similar impairment in the global cognitive function at the baseline to that in first-episode psychosis patients (79). In addition, the disease transition was predicted by multivariate pattern recognition of the neurocognitive performance (78).

Mismatch negativity (MNN) is a component of event-related potentials that reflects preattentive auditory sensory memory. MMN amplitudes are likely to provide an index of $\mathrm{N}$-methylD-aspartate (NMDA) receptor-mediated neurotransmissions (80-82). It has been reported that converters to psychosis elicit a reduced amplitude of duration MMN (dMMN), i.e., MMN in response to duration deviants, relative to non-converters (83-85). Hence, it may be possible to use dMMN to predict the conversion from ARMS to psychosis $(86,87)$.

Concerning the morphological changes in the brain, Koutsouleris et al. (88) revealed that ARMS patients with subsequent disease transition showed prefrontal alterations relative to those in ARMS patients without subsequent disease transition and healthy controls. Subsequently, Koutsouleris et al. (78) showed that the early prediction of psychosis may be reliably enhanced using neuroanatomical pattern recognition at the single-subject level.

A systematic review and meta-analysis (89) demonstrated decreased prefrontal, cingulate, insular, and cerebellar gray matter volumes in high-risk subjects with subsequent transition to psychosis compared with high-risk subjects without transition. In particular, the thickness of the anterior cingulate gyrus was significantly reduced in individuals with ARMS who later developed psychosis relative to healthy subjects $(47,90,91)$. These findings, together with those by Yamasue et al. (40) and Hao et al. (52), described in the previous section, suggest the crucial role of the anterior cingulate gyrus in the emergence of schizophrenic symptoms, in which self-disturbance might be fundamental $(92,93)$.

With regard to the dorsolateral frontal cortex, Reniers et al. (94) reported that lower baseline gray matter densities in the middle and inferior frontal gyri were significantly correlated with a decline in the GAF score over the follow-up, regardless of the transition status or persistence of ARMS. These findings along with the Kopelowicz et al's report (5) that frontal lobe functioning (executive function, verbal fluency, and verbal working memory) was associated with recovery from schizophrenia suggest the significance of the prefrontal lobe in social functioning and recovery from this condition.

Minnesota Multiphasic Personality Inventory, consisting of 550 questionnaires, is an established tool to assess personality and psychopathology (95). In our experience in the early intervention project, high scores on Scale 8 (schizophrenia) were associated with subsequent transition to psychosis (96). Subtle alterations of subjective experience may precede changes in objective measures as stated by Klosterkötter et al. (97) and Parnas and Handest (98).

Concerning the early intervention trials including antipsychotic medication or psychological intervention for ARMS patients, a meta-analysis of randomized controlled trials revealed that the overall risk of transition to psychosis was reduced by $54 \%$ at the 12-month follow-up (99). In view of the report that cognitive remediation improved memory and psychosocial functioning in first-episode psychiatric outpatients (100) and functional connectivity in early-course schizophrenia patients (101), cognitive remediation may also be effective for ARMS patients.

Whether early intervention in the prodromal phase significantly improves the long-term recovery rate of schizophrenia patients remains elusive. To answer this question, follow-up studies of ARMS patients who subsequently developed psychosis are needed.

In the next section, potential candidate compounds are described, capable of ameliorating the subclinical pathophysiological process, particularly, the histological brain changes in schizophrenia patients.

\section{A DIRECTION OF NOVEL THERAPEUTICS}

The understanding of the disease is composed of three levels: symptomatic, pathophysiological, and etiological. Therapeutics have been developed corresponding to these three levels. Current pharmacotherapy for schizophrenia remains at the symptomatic level, and so the long-term recovery rate has not changed, as described in the previous session. Owing to the recent development of technologies in neuroscience, our understanding of the pathophysiological disease process of schizophrenia has markedly progressed.

Olney and Farber (102) proposed that NMDA receptor hypofunction was a key mechanism that can help explain major clinical and pathophysiological aspects of schizophrenia, including the occurrence of structural brain changes, and stated that NMDA receptor hypofunction on GABAegic neurons would reduce inhibitory control over multiple downstream neurons.

Garey et al. (103). and Glantz and Lewis (104) reported a reduced dendritic spine density on pyramidal neurons in layer of the prefrontal and temporal cortex in postmortem brains of schizophrenia patients, and this was considered to explain the loss of cortical volume without the loss of neurons under this condition.

Furthermore, Reynolds et al. (105) and Zhang and Reynolds (106) reported a loss of parvalbumin-immunoreactive interneurons in the dorsolateral prefrontal cortex and hippocampus in schizophrenia patients. Chung et al. (107) demonstrated that the excitatory synapse density is selectively lower on parvalbumin interneurons in schizophrenia patients and that this may lead to the alterations of cortical gamma oscillations and working memory dysfunction.

Thus, a reduced dendritic spine density on pyramidal neurons and a loss of parvalbumin-immunoreactive interneurons in the cerebral cortex may be core features of histological changes in the brain of schizophrenia patients.

Importantly, animal models of schizophrenia, constructed on the basis of the NMDA receptor hypofunction hypothesis, successfully mimic these histological changes in the brain of schizophrenia.

Nakatani-Pawlak et al. (108) reported that mice neonatally treated with phencyclidine showed impairments of spatial working memory and social interaction behavior in adulthood, in 
addition to decreases in the number of parvalbumin-positive cells and spine density in the frontal cortex, nucleus accumbens, and hippocampus. Uehara et al. $(109,110)$ also reported augmented MAP-induced hyperlocomotion, sensorimotor gating deficits, and a loss of GABAergic parvalbumin-positive neurons in rats neonatally exposed to MK-801, an antagonist of the NMDA receptor.

Thus, utilizing these rodent animal models, it became possible to explore or develop novel therapeutics to improve cognitive deficits and the histological changes in the brain of schizophrenia patients.

There may be at least two approaches to develop novel therapeutics. One is to stimulate the glycine/D-serine modulatory site on the NMDA receptor with glycine (111) or D-serine (112). Another strategy is to explore medicines that ameliorate dysfunctional GABAergic neurons. The latter strategy is based on the concept that the hypofunction of NMDA receptors located on GABAergic neurons leads to the attenuated activity of GABAergic neurons, and this, in turn, produces abnormal gamma oscillations and cognitive deficits in schizophrenia patients (113).

Based on these lines, several candidate compounds have been reported. First, the ketamine-induced loss of parvalbuminpositive interneurons has been reported by an increase in brain superoxide due to the activation of NADPH oxidase in neurons (114). Subsequently, Zhang et al. (115) reported that apocynin, an inhibitor of NADPH oxidase, attenuated the cognitive impairments and downregulation of parvalbumin and glutamic acid decarboxylase 67 in rats after repeated ketamine exposure during the neonatal period.

Second, Shirai et al. (116) reported that the antioxidant sulforaphane, found in cruciferous vegetables, significantly attenuated hyperlocomotion and the prepulse inhibition deficits in mice after phencyclidine administration. Furthermore, the dietary intake of sulforaphane-rich broccoli sprout extracts attenuated cognitive deficits and the decrease in parvalbumin-positive cells in the medial prefrontal cortex and hippocampus of these mice (117).

Third, Uehara et al. $(110,118)$ found that T-817MA, a novel neurotrophic agent, restores parvalbumin-positive GABAergic neurons in the prefrontal cortex and hippocampus of the rat models described above. Haloperidol and risperidone showed no such effect. T-817MA is a newly synthesized agent that was developed for the treatment of neurodegenerative disorders, such as Alzheimer's disease, and it is markedly protective against $\mathrm{A} \beta$ induced or $\mathrm{H}_{2} \mathrm{O}_{2}$-induced neuronal death (119).

Furthermore, Nakamura et al. (120) reported that the oral administration of T-817MA ameliorated behavioral, histological, and neurophysiological changes, such as deficits in prepulse inhibition, reduced levels of parvalbumin-immunoreactive neurons in the medial prefrontal cortex, hippocampus, and amygdala, and a deficit in the auditory phase-locked gamma oscillation in a mouse model of schizophrenia. The modulation of gamma band activity is noteworthy, because abnormal gamma band activity is thought to underlie the psychosis and cognitive deficits, and is considered a target for potential therapeutic interventions (113).

These compounds have antioxidant effects in common (114, $116,119)$. In accordance with this, the antioxidant $N$-acetyl cysteine was reported to prevent the reduction of prefrontal parvalbumin interneuron activity as well as electrophysiological and behavioral deficits in the animal models of schizophrenia (121).

Considering that the dysfunction of parvalbumin-positive GABAergic neurons by NMDA receptor antagonists was mediated by oxidative mechanisms (114), some antioxidants might be novel therapeutics or lead compounds to ameliorate the cognitive deficits and histological disease process in schizophrenia patients.

\section{CONCLUSION}

Structural neuroimaging studies on schizophrenia revealed that volume reductions in the peri-Sylvian regions are mainly related to positive symptoms, whereas alterations in the fronto-thalamic regions are mainly related to negative symptoms, executive functions, and the functional outcome. These two types, i.e., the peri-Sylvian type and fronto-thalamic type, may provide a pathophysiological basis for Crow's (70) positive and negative syndrome classification. This model may explain why positive psychotic symptoms are not significantly correlated with the functional outcome, since it proposes that positive psychotic symptoms and functional outcomes are associated with distinct pathophysiology.

Accumulated evidence from early intervention trials suggests that the transition rate to psychosis is approximately $30 \%$ among individuals with ARMS. Differences in the cognitive performance, $\mathrm{MNN}$, and brain morphology have been reported between ARMS patients who later develop psychosis and those who do not. The prefrontal lobe function may have a significant role in social functioning and recovery from schizophrenia. Whether early intervention for ARMS significantly improves the long-term recovery rate of schizophrenia patients remains elusive.

With respect to the development of novel therapeutics, animal models of schizophrenia based on the $N$-methyl-D-aspartate receptor hypofunction hypothesis showed histological changes in the brain that successfully mimicked those in the postmortem brains of schizophrenia patients, i.e., decreased numbers of parvalbumin-positive interneurons and dendritic spines of pyramidal neurons in the frontal cortex, in addition to behavioral abnormalities associated with cognitive impairment. Some antioxidant compounds, e.g., apocynin, sulforaphane, and T-817MA, have been found to ameliorate histological changes in the brain and cognitive dysfunction in these animal models.

In conclusion, early intervention coupled with novel therapeutics, herein reviewed, may provide a promising strategy to substantially improve the functional outcome of schizophrenia patients. However, further studies are needed to evaluate the functional outcome in relation to these therapeutic strategies, which is beyond the scope of this review.

\section{AUTHOR CONTRIBUTIONS}

MK wrote the first draft of the manuscript. TT, TS, TU, and MS contributed to the cited studies and discussed the content of this manuscript. 


\section{REFERENCES}

1. Jääskeläinen E, Juola P, Hirvonen N, McGrath JJ, Saha S, Isohanni M, et al. A systematic review and meta-analysis of recovery in schizophrenia. Schizophr Bull (2013) 39:1296-306. doi:10.1093/schbul/sbs130

2. Jablensky A. Course and outcome of schizophrenia and their prediction. 2nd ed. In: Gelder MG, Andreasen NC, López-Ibor JJ Jr, Geddes JR, editors. New Oxford Textbook of Psychiatry. (Vol. 1), Oxford: Oxford University Press (2009). p. 568-78.

3. Green MF. What are the functional consequences of neurocognition deficits in schizophrenia? Am J Psychiatry (1996) 153:321-30. doi:10.1176/ajp.153.3.321

4. Green MF, Kern RS, Heaton RK. Longitudinal studies of cognition and functional outcome in schizophrenia; implication for MATRICS. Schizophr Res (2004) 72:41-51. doi:10.1016/j.schres.2004.09.009

5. Kopelowicz A, Liberman RP, Ventura J, Zarate R, Mintz J. Neurocogntive correlates of recovery from schizophrenia psychol. Psychol Med (2005) 35:1165-73. doi:10.1017/S0033291705004575

6. Higuchi Y, Sumiyoshi T, Seo T, Suga M, Takahashi T, Nishiyama S, et al. Associations between daily living skills, cognition, and real-world functioning across stages of schizophrenia; a study with the Schizophrenia Cognition Rating Scale Japanese version. Schizophr Res Cognition (2017) 7:13-8. doi:10.1016/j.scog.2017.01.001

7. Milev P, Ho B-C, Arndt S, Andreasen NC. Predictive values of neurocognition and negative symptoms on functional outcome in schizophrenia; a longitudinal first-episode study with 7-year follow-up. Am J Psychiatry (2005) 162:495-506. doi:10.1176/appi.ajp.162.3.495

8. Albert N, Bertelsen M, Thorup A, Petersen P, Le Quak P, Krarup G, et al. Predictors of recovery from psychosis. Analyses of clinical and social factors associated with recovery among patients with first-episode psychosis after 5 years. Schizophr Res (2011) 125:257-66. doi:10.1016/j.schres.2010.10.013

9. Davis KL, Buchsbaum MS, Shihabuddin L, Spiegel-Cohen J, Metzger M, Frecska E, et al. Ventricular enlargement in poor-outcome schizophrenia. Biol Psychiatry (1998) 43:783-93. doi:10.1016/S0006-3223(97)00553-2

10. Lieberman J, Chakos M, Wu HJ, Alvir J, Hoffman E, Robinson D, et al. Longitudinal study of brain morphology in first episode schizophrenia. Biol Psychiatry (2001) 49:487-99. doi:10.1016/S0006-3223(01)01067-8

11. van Haren NE, Hulshoff Pol HE, Schnack HG, Cahn W, Brans R, Carati I, et al. Progressive brain volume loss in schizophrenia over the course of the illness: evidence of maturational abnormalities in early adulthood. Biol Psychiatry (2008) 63:106-13. doi:10.1016/j.biopsych.2007.01.004

12. Ho BC, Andreasen NC, Nopoulos P, Arndt S, Magnotta V, Flaum M. Progressive structural brain abnormalities and their relationship to clinical outcome. A longitudinal magnetic resonance imaging study early in schizophrenia. Arch Gen Psychiatry (2003) 60:585-94. doi:10.1001/archpsyc.60.6.585

13. Brickman AM, Buchsbaum MS, Shihabuddin L, Byne W, Newmark RE, Brand J, et al. Thalamus size and outcome in schizophrenia. Schizophr Res (2004) 71:473-84. doi:10.1016/j.schres.2004.03.011

14. Mitelman SA, Shihabuddin L, Brickman AM, Hazlett EA, Buchsbaum MS. Volume of the cingulate and outcome in schizophrenia. Schizophr Res (2005) 72:91-108. doi:10.1016/j.schres.2004.02.011

15. Cahn W, van Haren NE, Hushoff Pol HE, Shnack HG, Caspers E, Laponde DA, et al. Brain volume changes in the first year of illness and 5-year outcome of schizophrenia. Br J Psychiatry (2006) 169:381-2. doi:10.1192/bjp.bp.105. 015701

16. MitelmanSA,NeumarkRE, Toros Jan Y, ChuKW,BrickmanAM,HaznedarMM, et al. White matter fractional anisotropy and outcome in schizophrenia. Schizophr Res (2006) 87:138-59. doi:10.1016/j.schres.2006.06.016

17. Wood SJ, Berger GE, Labert M, Conus P, Velakoulis D, Stuart GW, et al. Prediction of functional outcome 18 months after a first psychotic episode: a proton magnetic resonance spectroscopy study. Arch Gen Psychiatry (2006) 63:969-76. doi:10.1001/archpsyc.63.9.969

18. Wobrock T, Gruber O, Schneider-Axmann T, Wölwer W, Gaebel W, Riesbeck M, et al. Internal capsule size associated with outcome in first-episode schizophrenia. Eur Arch Psychiatry Clin Neurosci (2009) 259:278-83. doi:10.1007/ s00406-008-0867-y

19. Mitelman SA, Canfield EL, Chu KW, Brickman AM, Shihabuddin L, HazlettEA, et al. Poor outcome in chronic schizophrenia is associated with progressive loss of volume of the putamen. Schizophr Res (2009) 113:241-5. doi:10.1016/j. schres.2009.06.022
20. Mitelman SA, Canfield EL, Brickman AM, Shihabuddin L, Hazlett EA, Buchsbaum MS. Progressive ventricular expansion in chronic poor-outcome schizophrenia. Cogn Behav Neurol (2010) 23:85-8. doi:10.1097/ WNN.0b013e3181cfb52a

21. van Haren NE, Schnack HG, Cahn W, van den Heuvel MP, Lepage C, Collins L, et al. Changes in cortical thickness during the course of illness in schizophrenia. Arch Gen Psychiatry (2011) 68:871-80. doi:10.1001/ archgenpsychiatry.2011.88

22. Tully LM, Lincoln SH, Liyanage-Don N, Hooker CI. Impaired cognitive control mediates the relationship between cortical thickness of the superior frontal gyrus and role functioning in schizophrenia. Schizophr Res (2014) 152:358-64. doi:10.1016/j.schres.2013.12.005

23. Dusi N, Bellani M, Perlini C, Squarcina L, Marinelli V, Finos L, et al. Progressive disability and prefrontal shrinkage in schizophrenia patients with poor outcome: a 3-year longitudinal study. Schizophr Res (2017) 179:104-11. doi:10.1016/j.schres.2016.09.013

24. Shepherd AM, Laurens KR, Matheson SL, Carr VJ, Green MJ. Systematic meta-review and quality assessment of the structural brain alterations in schizophrenia. Neurosci Biobehav Rev (2012) 36:1342-56. doi:10.1016/j. neubiorev.2011.12.015

25. Seidman LJ, Faraone SV, Goldstein JM, Kremen WS, Horton NJ, Makris N, et al. Left hippocampal volume as a vulnerability indicator for schizophrenia. Arch Gen Psychiatry (2002) 59:839-49. doi:10.1001/archpsyc.59.9.839

26. Suzuki M, Zhou S-Y, Takahashi T, Hagion H, Kawasaki Y, Niu L, et al. Differential contributions of prefrontal and temporolimbic pathology to mechanisms of psychosis. Brain (2005) 128:2109-22. doi:10.1093/brain/ awh554

27. Boos HB, Aleman A, Cahn W, Hulshoff Pol H, Kahn RS. Brain volumes in relatives of patients with schizophrenia: a meta-analysis. Arch Gen Psychiatry (2007) 64:297-304. doi:10.1001/archpsyc.64.3.297

28. Olabi B, Ellison-Wright I, Macintosh AM, Wood SJ, Bullmore E, Lawrie SM. Are there progressive brain changes in schizophrenia? A meta-analysis of structural magnetic resonance imaging studies. Biol Psychiatry (2011) 70:88-96. doi:10.1016/j.biopsych.2011.01.032

29. Hirayasu Y, McCarley RW, Salisbury DF, Tanaka S, Kwon JS, Frumin M, et al. Planum temporale and Heschl gyrus volume reduction in schizophrenia: a magnetic resonance imaging study of first-episode patients. Arch Gen Psychiatry (2000) 57:692-9. doi:10.1001/archpsyc.57.7.692

30. Takahashi T, Suzuki M, Zhou SY, Tanaino R, Hagino H, Kawasaki Y, et al. Morphologic alterations of the parcellated superior temporal gyrus in schizophrenia spectrum. Schizophr Res (2006) 83:131-43. doi:10.1016/j. schres.2006.01.016

31. Kasai K, Shenton ME, Salisbury D, Hiyarasu Y, Lee CU, Ciszewski AA, et al. Progressive decrease of left superior temporal gyrus gray matter volume in patients with first-episode schizophrenia. Am J Psychiatry (2003) 160:156-64. doi:10.1176/appi.ajp.160.1.156

32. Takahashi T, Wood SJ, Yung AR, Soulsby B, McGoorry PD, Suzuki M, et al. Progressive gray matter reduction of the superior temporal gyrus during transition to psychosis. Arch Gen Psychiatry (2009) 66:366-76. doi:10.1001/ archgenpsychiatry.2009.12

33. Yoshida T, McCarley RW, Nakamura M, Lee K, Koo MS, Bouix S, et al. A prospective longitudinal volumetric MRI study of superior temporal gyrus gray matter and amygdala-hippocampal complex in chronic schizophrenia. Schizophr Res (2009) 113:84-94. doi:10.1016/j.schres.2009.05.004

34. Takahashi T, Wood SJ, Kawasaki Y, Suzuki M, Velakoulis D, Pantelis C. Lack of progressive gray matter reduction of the superior temporal subregions in chronic schizophrenia. Schizophr Res (2010) 117:101-2. doi:10.1016/j. schres.2009.12.034

35. Takahashi T, Suzuki M, Hagino H, Zhou SY, Kawasaki Y, Nohara S, et al. Bilateral volume reduction of the insular cortex in patients with schizophrenia: a volumetric MRI study. Psychiatry Res (2004) 132:187-96. doi:10.1016/j. pscychresns.2004.11.002

36. Takahashi T, Suzuki M, Zhou S-Y, Hagino H, Tanino R, Kawasaki Y, et al. Volumetric MRI study of the short and long insular cortices in schizophrenia spectrum disorders. Psychiatry Res (2005) 138:209-20. doi:10.1016/j. pscychresns.2005.02.004

37. Lee SH, Niznikiewicz M, Asami T, Otsuka T, Salisbury DF, Shenton ME, et al. Initial and progressive gray matter abnormalities in insular gyrus and temporal pole in first-episode schizophrenia contrasted with first-episode 
affective psychosis. Schizophr Bull (2016) 42:790-801. doi:10.1093/schbul/ sbv177

38. Takahashi T, Wood SJ, Soulsby B, McGorry PD, Tanino R, Suzuki M, et al. Follow-up MRI study of the insular cortex in first-episode psychosis and chronic schizophrenia. Schizophr Res (2009) 108:49-56. doi:10.1016/j.schres. 2008.12.029

39. Hazlett EA, Buchsbaum MS, Haznedar MM, Newmark R, Goldstein KE, Zelmanova $Y$, et al. Cortical gray and white matter volume in unmedicated schizotypal and schizophrenia patients. Schizophr Res (2008) 101:111-23. doi:10.1016/j.schres.2007.12.472

40. Yamasue H, Iwanami A, Hirayasu Y, Yamada H, Abe O, Kuroki N, et al. Localized volume reduction in prefrontal, tempolimbic, and paralimbic regions in schizophrenia: an MRI parcellation study. Psychiatry Res (2004) 131:195-207. doi:10.1016/j.pscychresns.2004.05.004

41. Johnstone EC, Crow TJ, Frith CD, Husband J, Kreel L. Cerebral ventricular size and cognitive impairment in chronic schizophrenia. Lancet (1976) 2:924-6. doi:10.1016/S0140-6736(76)90890-4

42. Yotsutsuji T, Saito O, Suzuki M, Hagino H, Mori K, Takahashi T, et al. Quantification of lateral ventricular subdivisions in schizophrenia by high-resolution there-dimensional magnetic resonance imaging. Psychiatry Res (2003) 122:1-12. doi:10.1016/S0925-4927(02)00105-1

43. Suzuki M, Nohara S, Hagino H, Kurokawa K, Yotsutsuji T, Kawasaki Y, et al. Regional changes in brain gray and white matter in patients with schizophrenia demonstrated with voxel-based analysis of MRI. Schizophr Res (2002) 55:41-54. doi:10.1016/S0920-9964(01)00224-9

44. Zhou SY, Suzuki M, Hagino H, Takahashi T, Kawasaki Y, Nohara S, et al. Decreased volume and increased asymmetry of the anterior limb of the internal capsule in patients with schizophrenia. Biol Psychiatry (2003) 54:427-36. doi:10.1016/S0006-3223(03)00007-6

45. Kawasaki Y, Suzuki M, Nohara S, Hagino H, Takahashi T, Matsui M, et al. Structural differences in patients with schizophrenia and schizotypal disorder demonstrated by voxel-based morphometry. Eur Arch Psychiatry Clin Neurosci (2004) 254:406-14. doi:10.1007/s00406-004-0522-1

46. Honea R, Crow TJ, Passingham D, Mackay CE. Regional deficits in brain volume in schizophrenia; a meta-analysis of voxel-based morphometry studies. Am J Psychiatry (2005) 162:2233-45. doi:10.1176/appi.ajp.162.12.2233

47. Fornito A, Yücel M, Patti J, Wood SJ, Pantelis C. Mapping grey matter reductions in schizophrenia: an anatomical likelihood estimation analysis of voxel-based morphometry studies. Schizophr Res (2009) 108:104-13. doi:10.1016/j.schres.2008.12.011

48. Asami T, Whitford TJ, Bouix S, Dickey CC, Niznikiewicz M, Shenton ME, et al. Globally and locally reduced MRI gray matter volumes in neuroleptic-naïve men with schizotypal personality disorder. JAMA Psychiatry (2013) 70:361-72. doi:10.1001/jamapsychiatry.2013.665

49. Siever LJ, Davis KL. The pathophysiology of schizophrenia disorders: perspectives from the spectrum. Am J Psychiatry (2004) 161:398-413. doi:10.1176/ appi.ajp.161.3.398

50. Kurachi M. Pathogenesis of schizophrenia: part II. Temporo-frontal two-step hypothesis. Psychiatry Clin Neurosci (2003) 57:9-15. doi:10.1046/j.1440-1819. 2003.01073.x

51. Honea RA, Meyer-Lindenberg A, Hobbs KB, Pezawas L, Mattay VS, Verhinski B, et al. Is gray matter volume an intermediate phenotype for schizophrenia? A voxel-based morphometry study of patients with schizophrenia and their healthy siblings. Biol Psychiatry (2008) 63:465-74. doi:10.1016/j.biopsych. 2007.05.027

52. Hao Y, Yan Q, Liu H, Xu L, Xue Z, Song X, et al. Schizophrenia patients and their healthy sibling share disruption of white matter integrity in the left prefrontal cortex and the hippocampus but not the anterior cingulated cortex. Schizophr Res (2009) 114:128-35. doi:10.1016/j.schres.2009.07.001

53. Barta PE, Pearlson GD, Powers RE, Richards SS, Tune LE. Auditory hallucinations and smaller superior temporal gyral volume in schizophrenia. Am J Psychiatry (1990) 147:1457-62. doi:10.1176/ajp.147.11.1457

54. Modinos G, Costafreda SG, van Tol M-J, Mcguire PK, Aleman A, Allin P. Neuroanatomy of auditory verbal hallucinations in schizophrenia: a quantitative meta-analysis of voxel-based morphometry studies. Cortex (2013) 49:1046-55. doi:10.1016/j.cortex.2012.01.009

55. Shenton ME, Kirkinis R, Jolesz FA, Pollak SD, LeMay M, Wible CG, et al. Abnormalities of the left temporal lobe and thought disorder in schizophrenia.
A quantitative magnetic resonance imaging study. $N$ Engl J Med (1992) 327:604-12. doi:10.1056/NEJM199208273270905

56. Horn H, Federspiel A, Wirth M, Müller TJ, Wies R, Wang JJ, et al. Structural and metabolic changes in language areas linked to formal thought disorder. $\mathrm{Br}$ J Psychiatry (2009) 194:130-8. doi:10.1192/bjp.bp.107.045633

57. Ingvar DH, Franzén G. Distribution of cerebral activity in chronic schizophrenia. Lancet (1974) 2:1484-6. doi:10.1016/S0140-6736(74)90221-9

58. Nenadic I, Sauer H, Gaser C. Distinct pattern of brain structural deficits in subsyndromes of schizophrenia delineated by psychopathology. Neuroimage (2010) 49:1153-60. doi:10.1016/j.neuroimage.2009.10.014

59. Uwatoko T, Yoshizumi M, Miyata J, Ubukata S, Fujiwara H, Kawada R, et al. Insular gray matter volume and objective quality of life in schizophrenia. PLoS One (2015) 10:e0142018. doi:10.1371/journal.pone.0142018

60. Minzenberg MJ, Laird AR, Thelen S, Carter CS, Glahn DC. Meta-analysis of 41 functional neruoimaging studies of executive function in schizophrenia. Arch Gen Psychiatry (2009) 66:811-22. doi:10.1001/archgenpsychiatry.2009.91

61. Kawada R, Yoshizumi M, Hirao K, Fujiwara H, Miyata J, Shimizu M, et al. Brain volume and dysexecutive behavior in schizophrenia. Prog Neuropsychopharmacol Biol Psychiatry (2009) 33:1255-60. doi:10.1016/j.pnpbp. 2009.07.014

62. Koh SD, Kayton L, Berry R. Mnemonic organization in young nonpsychotic schizophrenics. J Abnorm Psychol (1973) 81:299-310. doi:10.1037/h0034525

63. Matsui M, Suzuki M, Zhou S-Y, Takahashi T, Kawasaki Y, Yuuki H, et al. The relationship between prefrontal brain volume and characteristics of memory strategy in schizophrenia spectrum disorders. Prog Neuropsychopharmacol Biol Psychiatry (2008) 32:1854-62. doi:10.1016/j.pnpbp.2008.08.018

64. Keefe RSE, Mohs RC, Losonczy MF, Davidson M, Silverman JM, Kendler KS, et al. Characteristics of very poor outcome schizophrenia. Am J Psychiatry (1987) 144:889-95. doi:10.1176/ajp.144.7.889

65. Levitt JJ, Kubick M, Nestor PG, Ersner-Hershfield H, Westin CF, Alvarado JL, et al. A diffusion tensor imaging study of the anterior limb of the internal capsule in schizophrenia. Psychiatry Res (2010) 184:143-50. doi:10.1016/j. pscychresns.2010.08.004

66. Ferrarelli F, Huber R, Peterson MJ, Massimini M, Murphy M, Riedner BA, et al. Reduced sleep spindle activity in schizophrenia patients. Am J Psychiatry (2007) 164:483-92. doi:10.1176/ajp.2007.164.3.483

67. Buchmann A, Dentico D, Peterson MJ, Riedner BA, Sarasso S, Massimini M, et al. Reduced mediodorsal thalamic volume and prefrontal cortical spindle activity in schizophrenia. Neuroimage (2014) 102(Pt 2):540-7. doi:10.1016/j. neuroimage.2014.08.017

68. Ferrarelli F, Tononi G. Reduced sleep spindle activity point to a TRN-MD thalamus-PFC circuit dysfunction in schizophrenia. Schizophr Res (2017) 180:36-43. doi:10.1016/j.schres.2016.05.023

69. American Psychiatric Association. Diagnostic and Statistical Manual of Mental Disorders. 5th ed. Arlington, VA: American Psychiatric Association (2013).

70. Crow TJ. Molecular pathology of schizophrenia: more than one disease process? Br Med J (1980) 280:66-8. doi:10.1136/bmj.280.6207.66

71. Suzuki M, Nohara S, Hagino H, Takahashi T, Kawasaki Y, Yamashita I, et al. Prefrontal abnormalities in patients with simple schizophrenia: structural and functional brain-imaging studies in five cases. Psychiatry Res (2005) 140:157-71. doi:10.1016/j.pscychresns.2005.06.005

72. Borgwardt S, Piccioni MM, Ettinger U, Toulopoulou T, Murray R, McGuire PK. Regional gray matter volume in monozygotic twins concordant and discordant for schizophrenia. Biol Psychiatry (2010) 67:956-64. doi:10.1016/j. biopsych.2009.10.026

73. Hegelstad WT, Larsen TK, Auestad B, Evensen J, Haahr U, Joa I, et al. Longterm follow-up of the TIPS early detection in psychosis study: effects on 10-year outcome. Am J Psychiatry (2012) 169:374-80. doi:10.1176/appi.ajp. 2011.11030459

74. Yung A, McGorry PD. The prodromal phase of first-episode psychosis: past and current conceptualizations. Schizophr Bull (1996) 22:353-70. doi:10.1093/ schbul/22.2.353

75. Takahashi T, Wood SJ, Yung AR, Phillips LJ, Soulsby B, McGorry PD, et al. Insular cortex gray matter changes in individuals at ultra-high-risk of developing psychosis. Schizophr Res (2009) 111:94-102. doi:10.1016/j. schres.2009.03.024

76. Fusar-Poli P, Bonoldi I, Yung AR, Borgwardt S, Kempton MJ, Valmaggia L, et al. Predicting psychosis. Meta-analysis of transition outcomes in 
individuals at high clinical risk. Arch Gen Psychiatry (2012) 69:220-9. doi:10.1001/archgenpsychiatry.2011.1472

77. Brewer WJ, Francey SM, Wood SJ, Jackson HJ, Pantelis C, Phillips LJ, et al. Memory impairments identified in people at ultra-high risk for psychosis who later develop first-episode psychosis. Am J Psychiatry (2005) 162:71-8. doi:10.1176/appi.ajp.162.1.71

78. Koutsouleris N, Davatzikos C, Bottlender R, Patschurek-Kliche K, Scheuerecker J, Decker P, et al. Early recognition and disease prediction in the at-risk mental states for psychosis using neurocognitive pattern classification. Schizophr Bull (2012) 38:1200-15. doi:10.1093/schbul/sbr037

79. Simon AE, Grädel M, Cattapan-Ludewig K, Gruber K, Ballinari ZP, Roth B, et al. Cognitive functioning in at-risk mental states for psychosis and 2-year clinical outcome. Schizophr Res (2012) 142:108-15. doi:10.1016/j. schres.2012.09.004

80. Umbricht D, Koller R, Vollenweider FX, Schmid L. Mismatch negativity predicts psychotic experiences induced by NMDA receptor antagonist in healthy volunteers. Biol Psychiatry (2002) 51:400-6. doi:10.1016/S0006-3223 (01)01242-2

81. Rosburg T, Kreitschmann-Andermahr I. The effects ketamine on the mismatch negativity (MMN) in humans - a meta-analysis. Clin Neurophysiol (2016) 127:1387-94. doi:10.1016/j.clinph.2015.10.062

82. Avissar M, Javitt D. Mismatch negativity: a simple and useful biomarker of $\mathrm{N}$-methyl-D-aspartate receptor (NMDAR)-type glutamate dysfunction in schizophrenia. Schizophr Res (2018) 191:1-4. doi:10.1016/j.schres.2017.11.006

83. Bodatsch M, RuhrmannS, Wagner M, Müller R, Schultze-Lutter F, Frommann I, et al. Prediction of psychosis by mismatch negativity. Biol Psychiatry (2011) 69:959-66. doi:10.1016/j.biopsych.2010.09.057

84. Shaikh M, Valmaggia L, Broome MR, dutt A, Lappin J, Day F, et al. Reduced mismatch negativity predates the onset of psychosis. Schizophr Res (2012) 134:42-8. doi:10.1016/j.schres.2011.09.022

85. Higuchi Y, Sumiyoshi T, Seo T, Miyanishi T, Kawasaki Y, Suzuki M. Mismatch negativity and cognitive performance for the prediction of psychosis in subjects with at-risk metal state. PLoS One (2013) 8(1):e54080. doi:10.1371/ journal.pone. 0054080

86. Nagai T, Tada M, Kirihara K, Araki T, Jinde S, Kasai K. Mismatch negativity as "translatable" brain marker toward early intervention for psychosis: a review. Front Psychiatry (2013) 4:115. doi:10.3389/fpsyt.2013.00115

87. Nääänen R, Todd J, Schall U. Mismatch negativity (MMN) as biomarker predicting psychosis in clinically at-risk individuals. Biol Psychiatry (2016) 116:36-40. doi:10.1016/j.biopsycho.2015.10.010

88. Koutsouleris N, Schmitt GJE, Gaser C, Bottlender R, Scheuerecker J, McGuire P, et al. Neuroanatomical correlates of different vulnerability states for psychosis and their clinical outcomes. Br J Psychiatry (2009) 195:218-26. doi:10.1192/bjp.bp.108.052068

89. Smieskova R, Fusar-Poli P, Allen P, Bendfeldt K, Stieglitz RD, Drewe J, et al. Neuroimaging predictors of transition to psychosis - a systematic review and meta-analysis. Neurosci Biobehav Rev (2010) 34:1207-22. doi:10.1016/j. neubiorev.2010.01.016

90. Nakamura K, Takahashi T, Nemoto K, Furuichi A, Nishiyama S, Nakamura Y, et al. Gray matter changes in subjects at high risk for developing psychosis and first-episode schizophrenia: a voxel-based structural MRI study. Front Psychiatry (2013) 4:16. doi:10.3389/fpsyt.2013.00016

91. Takayanagi Y, Kulason S, Sasabayashi D, Takahashi T, Katgiri N, Sakuma A, et al. Reduced thickness of the anteiror cingulate cortex in individuals with an at-risk mental state who later develop psychosis. Schizophr Bull (2017) 143:907-13. doi:10.1093/schbul/sbw167

92. Nelson B, Fornito A, Harrison BJ, Yücel M, Sass LA, Yung AR, et al. A disturbed sense of self in the psychosis prodrome: linking phenomenology and neurobiology. Neurosci Biobehav Rev (2009) 33:807-17. doi:10.1016/j. neubiorev.2009.01.002

93. Nelson B, Thompson A, Yung AR. Basic self-disturbance predicts psychosis onset in the ultra high risk for psychosis "prodromal" population. Schizophr Bull (2012) 38:1277-87. doi:10.1093/schbul/sbs007

94. Reniers RL, Lin A, Yung AR, Koutsouleris N, Nelson B, Cropley VL, et al. Neuroanatomoical predictors of functional outcome in individuals at ultrahigh risk for psychosis. Schizophr Bull (2017) 43:449-58. doi:10.1093/schbul/ sbw086

95. Graham JR. MMPI-2. 5th ed. Oxford: Oxford University Press (2012).
96. Nishiyama S, Higuchi Y, Komori Y, Takahashi T, Suzuki M. Personality characteristics prior to the onset of overt psychosis in individuals at ultra-high risk for psychosis. The 21st Annual Meeting of Japanese Society for Prevention and Early Intervention in Psychiatry. Okinawa (2017) 12:9-10.

97. Klosterkötter J, Schultze-Lutter F, Gross G, Huber G, Steinmeyer EM. Early self-experienced neuropsychological deficits and subsequent schizophrenic diseases: an 8-year average follow-up prospective study. Acta Psychiatr Scand (1997) 95:396-404. doi:10.1111/j.1600-0447.1997.tb09652.x

98. Parnas J, Handest P. Phenomenology of anomalous self-experience in early schizophrenia. Compr Psychiatry (2003) 44:121-34. doi:10.1053/ comp.2003.50017

99. van der Gaag M, Smit F, Bechdolf A, French P, Linszen DH, Yung AR, et al. Preventing a first episode of psychosis: meta-analysis of randomized controlled prevention trials of 12 month and longer-term follow-ups. Schizophr Res (2013) 149:56-62. doi:10.1016/j.schres.2013.07.004

100. Lee RS, Redoblado-Hodge MA, Naismith SL, Hermens DF, Porter MA, Hickie IB. Cognitive remediation improves memory and psychosocial functioning in first-episode psychotic out-patients. Psychol Med (2013) 43:1161-73. doi:10.1017/S0033291712002127

101. Eack SM, Newhill CE, Keshavan MS. Cognitive enhancement therapy improves resting-state functional connectivity in early course schizophrenia. J Soc Soc Work Res (2016) 7:211-30. doi:10.1086/686538

102. Olney JW, Farber NB. Glutamate receptor dysfunction and schizophrenia Arch Gen Psychiatry (1995) 52:998-1007. doi:10.1001/archpsyc.1995. 03950240016004

103. Garey LJ, Ong WY, Patel TS, Kanani M, Davis A, Mortimer AM, et al. Reduced dendritic spine density on cerebral cortical pyramidal neurons in schziopohrenia.J Neurol Neurosurg Psychiatry (1998) 65:446-53. doi:10.1136/ jnnp.65.4.446

104. Glantz LA, Lewis DA. Decreased dendritic spine density on prefrontal cortical pyramidal neurons in schizophrenia. Arch Gen Psychiatry (2000) 57:65-73. doi:10.1001/archpsyc.57.1.65

105. Reynolds GP, Beasley CL, Zhang ZJ. Understanding the neurotransmitter pathology of schizophrenia: selective deficits of subtypes of cortical GABAergic neurons. J Neural Transm (2002) 109:881-9. doi:10.1007/ s007020200072

106. Zhang ZJ, Reynolds GP. A selective decrease in the relative density of parvalbumin-immnoreactive neurons in the hippocampus in schizophrenia. Schizophr Res (2002) 55:1-10. doi:10.1016/S0920-9964(01)00188-8

107. Chung DW, Fish KN, Lewis DA. Pathological basis for deficient excitatory drive to cortical parvalbumin interneurons in schizophrenia. Am J Psychiatry (2016) 173:1131-9. doi:10.1176/appi.ajp.2016.16010025

108. Nakatani-Pawlak A, Yamaguchi K, Tatsumi Y, Mizoguchi H, Yoneda Y. Neonatal phencyclidine treatment in mice induces behavioral, histological and neurochemical abnormalities in adulthood. Biol Pharm Bull (2009) 32:1576-83. doi:10.1248/bpb.32.1576

109. Uehara T, Sumiyoshi T, Seo T, Matusoka T, Itoh H, Susuki M, et al. Neonatal exposure to MK-801, an N-Methyl-D-aspartate receptor antagonist, enhances methamphetamine-induced locomotion and disrupts sensorimoter gating in pre- and postpubertal rats. Brain Res (2010) 1352:223-30. doi:10.1016/j. brainres.2010.07.013

110. Uehara T, Sumiyoshi T, Hattori H, Itoh $\mathrm{H}$, Matsuoka T, Iwakami N, et al. T-817, a novel neurotrophic agent, ameliorates loss of GABAergic parvalbumin-positive neurons and sensorimotor gating deficits in rats transiently exposed to MK-801 in the neonatal periods. J Psychiatr Res (2012) 46:622-9. doi:10.1016/j.jpsychires.2012.01.022

111. Woods SW, Walsh BC, Hawkins KA, Miller TJ, Saksa JR, D’Souza DC, et al. Glysine treatment of the risk syndrome for psychosis: report of two pilot studies. Eur Neuropsychopharmacol (2013) 23:931-40. doi:10.1016/j. euroneuro.2012.09.008

112. Kantrowitz J, Woods SW, Petkova E, Cornblatt B, Corcoran CM, Chen H, et al. D-serine for the treatment of negative symptoms in individuals at clinical high risk of schizophrenia: a pilot, double-blind, placebo-controlled, randomised parallel group mechanistic proof-of-concept trial. Lancet Psychiatry (2015) 2:403-12. doi:10.1016/S2215-0366(15)00098-X

113. McNally JM, McCarley RW. Gamma band oscillations: a key to understanding schizophrenia symptoms and neural circuit abnormalities. Curr Opin Psychiatry (2016) 29:202-10. doi:10.1097/YCO.0000000000000244 
114. Behrens MM, Ali SS, Dao DN, Lucero J, Shekhtman G, Quick KL, et al. Ketamine-induced loss of phenotype of fast-spiking interneurons is mediated by NADPH-oxidase. Science (2007) 318:1645-7. doi:10.1126/ science. 1148045

115. Zhang H, Sun XR, Wang J, Zhang ZZ, Zhao HT, Li HH, et al. Reactive oxygen species-mediated loss of phenotype of parvalbumin interneurons contributes to long-term cognitive impairments after repeated neonatal ketamin exposures. Neurotox Res (2016) 30:593-605. doi:10.1007/s12640-016-9653-1

116. Shirai Y, Fujita Y, Hashimoto R. Effects of the antioxidant sulforaphane on hyperlocomotion and prepulse inhibition deficits in mice after phencyclidine administration. Clin Psychopharmacol Neurosci (2012) 10:94-8. doi:10.9758/ cpn.2012.10.2.94

117. Shirai Y, Fujita Y, Hashimoto R, Ohi K, Yamamori H, Yasuda Y, et al. Dietary intake of sulforaphane-rich broccoli sprout extracts during juvenile and adolescence can prevent phencyclidine-induced cognitive deficits at adulthood. PLoS One (2015) 10(6):eO127244. doi:10.1371/journal.pone.0127244

118. Uehara T, Sumiyoshi T, Seo T, Matsuoka T, Itoh H, Kurachi M. T-817MA, but not haloperidol and risperidone, restores parvalbumin-positive $\gamma$-aminobutyric acid neurons in the prefrontal cortex and hippocampus or rats transiently exposed to MK-801 at the neonatal period. ISRN Psychiatry (2012) 2012:947149. doi:10.5402/2012/947149

119. Hirata K, Yamaguchi H, Takamura Y, Takagi A, Fukushima T, Iwakami N, et al. A novel neurotrophic agent, T-817MA [1-\{3-[2-(1-benzothophen-5-yl) ethoxy] propyl\}-3-azetidinol maleated], attenuates amyoid- $\beta$-induced neurotoxicity and promotes neurite outgrowth in rat cultured central nervous system neurons. J Pharmacol Exp Ther (2005) 314:252-9. doi:10.1124/ jpet.105.083543

120. Nakamura T, Matsujoto J, Takamura Y, Ishii Y, Sasahra M, Ono T, et al. Relationships among parvalbumin-immunoreactive neuron density, phase-locked gamma oscillations, and autistic/schizophrenic symptoms in PDGFR- $\beta$ knock-out and control mice. PLoS One (2015) 10(3):e0119258. doi:10.1371/journal.pone.0119258

121. Cabungcal JH, Counotte DS, Lewis E, Tejeda HA, Piantadosi P, Pollock C, et al. Juvenile antioxidant treatment prevents adult deficits in a developmental model of schizophrenia. Neuron (2014) 83:1073-84. doi:10.1016/j. neuron.2014.07.028

Conflict of Interest Statement: The authors declare that the research was conducted in the absence of any commercial or financial relationships that could be construed as a potential conflict of interest.

Copyright (c) 2018 Kurachi, Takahashi, Sumiyoshi, Uehara and Suzuki. This is an open-access article distributed under the terms of the Creative Commons Attribution License (CC BY). The use, distribution or reproduction in other forums is permitted, provided the original author(s) and the copyright owner are credited and that the original publication in this journal is cited, in accordance with accepted academic practice. No use, distribution or reproduction is permitted which does not comply with these terms. 